\title{
MEDICINE
}

\section{ХАРАКТЕРИСТИКА МИКРОБИОЦИНОЗА ПОЛОСТИ РТА У ПАЦИЕНТОВ С ПОЛНЫМ ОТСУТСТВИЕМ ЗУБОВ ДО ЛЕЧЕНИЯ И ПОСЛЕ ВНУТРИКОСТНОЙ ИМПЛАНТАЦИИ}

Добровольская О. В., дочент, к.мед.н., Добровольский А. В., дочент, к.мед.н., Дворник В. Н., проректор, профессор, д.мед.н.

Украинская медииинская стоматологическая академия, г. Полтава, Украина

Кафедра ортопедической стоматологии с имплантологией

DOI: https://doi.org/10.31435/rsglobal_sr/30122019/6861

\section{ARTICLE INFO}

Received 19 October 2019 Accepted 10 December 2019 Published 30 December 2019

\section{KEYWORDS}

dental implantation, complete adentia, oral microbiocenosis.

\begin{abstract}
A qualitative, or species, study of the microflora of the oral cavity was carried out using the technique of aerobic and anaerobic cultivation in patients with a full adentia of the upper and lower jaw before and after implantation. In patients after dental implantation, a change was observed both in the qualitative composition of the flora (the frequency of isolation of certain species) and the number of microbes secreted, which, in addition, underwent a certain dynamics on the 7th and 14th days of observation. On the 7th and further, on the 14th day of the study, a gradual decrease in the proportion of obligate-anaerobic and, above all, virulent periodontopathogenic species was observed (although their complete disappearance did not occur). In addition, the number of stabilizing microbial species was restored and was approaching normal. As a positive fact, indicating the favorable results of the surgical stage of treatment, it should also be noted that the number of most pathogenic species decreased by the 14th day from the moment of surgery to the minimum values.
\end{abstract}

Citation: Oksana Dobrovolska, Oleksandr Dobrovolskyi, Valentin Dvornik. (2019) Characteristic of Microbiocenosis of the Oral Cavity in Patients with a Total Absence of Dentals Before Treatment and After Dental Implantation. Science Review. 9(26). doi: 10.31435/rsglobal_sr/30122019/6861

Copyright: C 2019 Oksana Dobrovolska, Oleksandr Dobrovolskyi, Valentin Dvornik. This is an openaccess article distributed under the terms of the Creative Commons Attribution License (CC BY). The use, distribution or reproduction in other forums is permitted, provided the original author(s) or licensor are credited and that the original publication in this journal is cited, in accordance with accepted academic practice. No use, distribution or reproduction is permitted which does not comply with these terms.

Состояние микробиоценоза полости рта при полном отсутствии зубов до и в процессе лечения требует постоянного изучения и осмысления в связи с внедрением новых материалов и технологий, в том числе и совершенствованием методов имплантации (Jansen V., Conrads G., Richter E., 1997). Имплантация приводит к значительным реакциям местного иммунитета в виде перегруппировки клеточных элементов как «линии защиты» у входных ворот инфекции $[1,2,3]$. Микробная инвазия в периимплантатную область является одной из основных причин отдаленных осложнений данного метода лечения, приводящей к воспалению тканей и быстрой потере кости (Базикян Э.А., 2001; Сергеев А.А., 2005; Rams T.E. et al.)

В полости рта протез подвергается колонизации микроорганизмами, на его поверхности создается биопленка. Микроорганизмы внедряются на 1,2 - 3 мм в толщу пластмассы. (Сысоев И.П., 1992). Микробная обсемененность увеличивается при увеличении возраста пациента, удлинении срока пользования протезами, улучшении их фиксации, несоблюдении гигиены полости рта (Тер-Погосян Е.М., Олсйник 3.А., Петрова Г.П., 1975). [4,5]. 
Цель исследования. Изучить исходное состояние микробиоценоза полости рта у пациентов с полным отсутствием зубов на верхней и нижней челюсти и его изменение при использовании дентальных имплантатов для улучшения фиксации съемного протеза.

Материалы и методы. В проведении мониторинга микробиоценоза слизистой оболочки полости рта в зоне имплантации и протезирования участвовали 40 пациентов с полным отсутствием зубов на верхней и нижней челюсти, разделенных на две группы:

1 группа - 20 пациентов после установки 2-4 имплантатов в области верхней и нижней челюсти с последующим наложением полного съемного перекрывающего протеза с балочной фиксацией, металлическим каркасом и пластмассовым базисом;

2 группа - 20 пациентов с полным отсутствием зубов на нижней и верхней челюсти, до лечения с помощью имплантатов.

Забор материала для микробиологического исследования у пациентов с полным отсутствием зубов до протезирования и на 3-й, 7-е и 14-е сутки после имплантации (без протезов) осуществляли с помощью адгезивной, неевгеноловой пленки «Ora-Aid» стандартного размера 0,5 $\mathrm{cm}^{2}$ (стерильная мембрана, предназначенная в качестве барьера при хирургических вмешательствах на пародонте), которая накладывалась на поверхность слизистой оболочки. Забор материала с поверхности лечебного аппарата также производили с помощью адгезивной пленки на 7, 14 и 30-е сутки после его установки для сопоставимого исследования флоры, покрывающей протез (протезной биоплёнки). Пленка с микрофлорой переносилась в транспортную среду Стюата (1 мл), растворялась в ней и использовалась для дальнейшего количественного исследования микробов, снятых таким образом с поверхности лечебного аппарата.

Вид питательной среды и время последующей инкубации определялось задачей качественного исследования микрофлоры. Исследования по описанной методике осуществляли в отношении двух групп микроорганизмов полости рта:

1 - резидентной, или стабилизирующей, группы, которая играет стабилизирующую роль в микробиоценозе полости рта (микроаэрофильные стрептококки Streptococcus sanguis, Streptococcus a-gr.; Actinomyces spp. S. mutans, Enterococcus spp., Peptostreptococcus, Veillonella, бактероиды Prevotella oralis);

2 - вирулентной или пародонтопатогешшой группы, которая обладает факторами вирулентности и может поддерживать развитие различных воспалительных процессов в полости рта (актиномицеты Actinomyces naeslundii, Actinomyces israelii; бактероиды Prevotella melaninogcnica, Porphyromonas gingivalis; фузобактерии Fusobacterium spp).

Качественное, или видовое, изучение микрофлоры полости рта проводили с использованием техники аэробного и анаэробного культивирования. Для этого осуществляли несколько видов посевов исследуемого материала:

a) на 5\% кровяной гемин-агар - для последующего культивирования в апаэростатс с газовым составом $80 \%$ азота, $20 \%$ углекислого газа (до 7-ми суток);

б) на 5\% кровяной агар - для культивирования в обычных условиях (до 2-х суток);

в) на среду Эндо - для культивирования в обычных условиях для выделения представителей семейства Enterobacteriaceae (до 2-х суток);

г) на среду Сабуро - для культивирования в обычных условиях для выделения грибов, в частности, дрожжеиодобных рода Candida (до 3-х суток).

Во всех случаях культивирование проводили при $37^{\circ}$ С. После выделения изолированных колоний получали чистые культуры бактерий и грибов на сердечно-мозговом агаре или полужидкой среде АC и осуществляли их идентификацию по комплексу морфологических, культуральных и биохимических признаков с использованием «ключа» для идентификации микроорганизмов полости рта.

Результаты исследования. На основании числа колоний, выросших в первичном посеве, определяли содержание каждого вида бактерий из расчёта на $1 \mathrm{~cm}^{2}$ адгезивной пленки для взятия, материала $\left(\mathrm{CFU} / \mathrm{cm}^{2}\right)$. Исследования проведены на кафедре микробиологии, иммунологии и вирусологии Украинской медицинской стоматологической академии.

Нами были сопоставлены данные по состоянию микробиоценоза полости рта у пациентов после установки внутрикостных имплантатов. Результаты исследования микробной флоры слизистой оболочки полости рта в зоне предполагаемой имплантации и после неё представлены в табл. 1-2. Из анализа полученных данных следует, что у пациентов 1-, 2- й 
групп показатель микробной обсеменённости слизистой оболочки полости рта до лечения совпадал и составлял $10^{5}+10^{2} \mathrm{CFU}$, что находилось в пределах данных для нормальной слизистой оболочки полости рта у практически здоровых людей (от $10^{4}$ до $\left.10^{6} \mathrm{CFU}\right)$.

Таблица 1. Качественный (видовой) состав микробной флоры полости рта у пациентов 2-й группы до протезирования

\begin{tabular}{|l|l|l|l|l|}
\hline \multicolumn{1}{|c|}{$\begin{array}{c}\text { Родр, ВИд } \\
\text { микроорганизмов }\end{array}$} & $\begin{array}{c}\text { Число } \\
\text { Пациентов } \\
\text { N=20 }\end{array}$ & $\begin{array}{c}\text { Частота (\% от } \\
\text { числа пациентов) }\end{array}$ & $\begin{array}{c}\text { Видовой состав } \\
\text { (\% от числа } \\
\text { штаммов) }\end{array}$ & \multicolumn{1}{|c|}{$\begin{array}{c}\text { Микробное } \\
\text { число } \\
\text { (CFU) }\end{array}$} \\
\hline Streptococcus sanguis & 20 & 100,0 & 19,6 & $10^{\prime \prime}-10^{\text {й }}$ \\
\hline Streptococcus a -gr. & 14 & 70,0 & 15,7 & $10^{4}-10^{\mathrm{b}}$ \\
\hline Enicrococcus spp. & 11 & 55,0 & 12,8 & $10^{4}$ \\
\hline Actinomyces spp. & 12 & 60,0 & 11,8 & $10^{*}$ \\
\hline Fusobacterium spp. & 12 & 60,0 & 11,8 & $10 \mathrm{Mo}^{4}$ \\
\hline Prcvotclla oralis & 9 & 45,0 & 8,8 & $10^{4}$ \\
\hline Vcilloncllaspp. & 7 & 35,0 & 6,7 & $10^{\mathrm{j}}$ \\
\hline Enterobacterium spp. & 6 & 35,0 & 6,7 & $10^{\prime}-10^{4}$ \\
\hline Прочие & 7 & 30,0 & 5,9 & $10^{b} \pm 10^{2}$ \\
\hline Bсего штаммов & 98 & 100,0 & 100,0 & \\
\hline
\end{tabular}

По качественному составу микробная флора пациентов двух групп была представлена типичными представителями стабилизирующих видов: Streptococcus sanguis, Streptococcus ctgr., Actinomyces spp. Они были выделены у 58,8-100\% пациентов. Несколько реже (у 35-45\%) встречались такие представители стабилизирующей флоры как Veillonella spp., Prevotclla oralis.

Количество микробов перечисленных видов находилось в пределах $10^{3}-10^{6} \mathrm{CFU}$, что соответствовало нормальным показателям. Обращала на себя внимание более низкая частота содержания представителей группы Lactobacillus и Neisseria у пациентов всех групп.

В тоже время, несколько чаще, чем у практически здоровых людей встречались энтерококки (64-65\%), актиномицеты (58,8-60\%), фузобактерии (52,9-60\%) и эптеробактерии (35\%), которые могут поддерживать воспалительный процесс. Однако их количество было низким и не превышало величину $10^{4} \mathrm{CFU}$.

У $30 \%$ пациентов выделяли прочие виды бактерий. Однако их доля от общего числа штаммов во всех группах была незначительной (5,9\%) -стафилококки, лактобациллы и нейссерии выделяли в единичных случаях, причём в незначительном количестве $\left(10^{\mathrm{J}}, 10^{\mathrm{J}}\right.$ и $10^{*}$ CFU соответственно). Ни в одном случае не обнаружены синсгнойная палочка, клебсиеллы, бациллы, дрожжей одобные грибы кандида, выделение которых принято считать неблагоприятным гигиеническим признаком состояния слизистой оболочки полости рта. Принципиальных различий качественного и количественного состава микробов в сравниваемых группах до проведения имплантации нами выявлено не было. Общая микробная обсемененность слизистой оболочки находилась в пределах нормы $\left(10^{5} \pm 10^{2} \mathrm{CFU}\right)$.

У пациентов 1 группы (табл. 2), которым устанавливали от 2-х до 4-х имплантатов на верхней и нижней челюсти, на 3-ьи сутки наблюдали следующую картину изменения микробиоценоза по сравнению с данными обследования, полученными до имплантации. Частота выделения Streptococcus sanguis, Streptococcus ct-gr., Actinomyces spp. - основных стабилизирующих видов менялась незначительно. Представители данных видов выделялись у $47-100 \%$ обследованных. Существенно увеличивалась частота выделения энтерококков (с 64,7 до $82,3 \%$ пациентов). В рассматриваемой группе несколько увеличивалось количество облигатно-анаэробных видов за счёт представителей Fusobacterium spp. (с 52,9 до 70,5\% пациентов). Выявлены также представители облигатно-анаэробных вирулентных видов: Prevotclla melaninogenica, Porphyromonas gingivalis, Actinomyces israelii. Общее число этих видов составило 9,9\% всего микробного пейзажа. 
Таблица 2. Качественный (видовой) состав микробной флоры полости рта у пациентов 1-й группы до имплантации и на третьи сутки после установки 2 - 4-х имплантатов

\begin{tabular}{|c|c|c|c|c|c|c|c|c|}
\hline \multirow[t]{2}{*}{$\begin{array}{c}\text { Род, вид } \\
\text { микроорганизмов }\end{array}$} & \multicolumn{2}{|c|}{$\begin{array}{c}\text { Число } \\
\text { пациентов } \\
(\Pi=20)\end{array}$} & \multicolumn{2}{|c|}{$\begin{array}{c}\text { Частота } \\
\text { (\% от числа } \\
\text { пациентов). }\end{array}$} & \multicolumn{2}{|c|}{$\begin{array}{c}\text { Видовой состав } \\
\text { (\% от числа } \\
\text { штаммов) }\end{array}$} & \multicolumn{2}{|c|}{$\begin{array}{l}\text { Микробное } \\
\text { число } \\
\text { (CFU) }\end{array}$} \\
\hline & $\begin{array}{c}\text { до } \\
\text { импл. }\end{array}$ & $\begin{array}{l}\text { после } \\
\text { импл. }\end{array}$ & $\begin{array}{c}\text { до } \\
\text { импл. }\end{array}$ & $\begin{array}{l}\text { после } \\
\text { импл. }\end{array}$ & $\begin{array}{c}\text { до } \\
\text { импл. }\end{array}$ & $\begin{array}{l}\text { после } \\
\text { импл. }\end{array}$ & $\begin{array}{c}\text { до } \\
\text { импл. }\end{array}$ & $\begin{array}{l}\text { после } \\
\text { импл. }\end{array}$ \\
\hline Streptococcus sanguis & 20 & 17 & 100,0 & 100,0 & 19,6 & 18,7 & $10^{4}-10^{\mathrm{b}}$ & $10^{6}-10^{7}$ \\
\hline Streptococcus a -gr. & 16 & 11 & 80,0 & 64,7 & 15,7 & 12,1 & $10^{4}-10^{6}$ & $10^{4}-10^{6}$ \\
\hline Enterococcus spp. & 13 & 14 & 65,0 & 82,3 & 12,8 & 15,4 & $10^{4}-10^{6}$ & $10^{4}-10^{6}$ \\
\hline $\begin{array}{l}\text { Actinomyces spp. в т.ч.: } \\
\text { A.israelii }\end{array}$ & 12 & $\begin{array}{l}8 \\
2\end{array}$ & 60,0 & $\begin{array}{l}47,1 \\
11,8\end{array}$ & 11,8 & $\begin{array}{l}8,8 \\
2,2\end{array}$ & - $10^{4}$ & $\begin{array}{l}10^{4}-10^{5} \\
10^{3}\end{array}$ \\
\hline Fusobacterium spp. & 12 & 12 & 60,0 & 70,5 & 11,8 & 13,2 & $10^{\prime}-10^{4}$ & $10^{4}-10^{5}$ \\
\hline Prevotella oralis & 9 & 7 & 45,0 & 41,2 & 8,8 & 7,7 & $10^{4}-10^{5}$ & $10^{4}-10^{3}$ \\
\hline Veillonella spp. & 7 & 7 & 35,0 & 41,2 & 6,7 & 7,8 & $10^{4}$ & $10^{\mathrm{i}}$ \\
\hline Enterobacterium spp. & 7 & 6 & 35,0 & 35,3 & 6,7 & 6,6 & $10^{\mathrm{J}}-10^{4}$ & $10^{\mathrm{i}}-1 \mathrm{o}^{4}$ \\
\hline $\begin{array}{l}\text { Прочие } \\
\text { в т.ч.; P.melaninog. } \\
\text { Porphyrom.gingivalis }\end{array}$ & 6 & $\begin{array}{l}93 \\
2\end{array}$ & 30,0 & $\begin{array}{l}52,9 \\
42,9 \\
11,8\end{array}$ & 5,9 & $\begin{array}{l}9,93,3 \\
2,2\end{array}$ & $10^{2}-10^{4}$ & $\begin{array}{l}10^{\mathrm{J}}-1 \mathrm{o}^{4} \\
10^{5} \mathrm{I} 0^{4}\end{array}$ \\
\hline Всего штаммов & 102 & 91 & 100,0 & 100,0 & 100,0 & 100,0 & $10^{\mathrm{s}}+10^{2}$ & $10^{5}+10^{\wedge}$ \\
\hline
\end{tabular}

При дальнейшем наблюдении за структурой микрофлоры и сопоставлением данных, полученных на 3-й, 7-е и 14-е сутки после дентальной имплантации, не выявлено существенных изменений качественного состава микробной флоры. Однако, наблюдалась статистически достоверная динамика количественной обсеменённости послеоперационной раны (микробного числа) представителями как стабилизирующих, так и вирулентных видов.

На 7-е сутки количество стрептококков, альфа-зеленящих стрептококков и энтерококков значительно увеличивалось, достигая $10^{7} \mathrm{CFU}$ (в логарифмическом выражении $7,0)$. Среди других стабилизирующих видов заслуживает внимания динамика содержания Peptostreptococcus spp. и VeiUonella spp. На 3-й сутки эти бактерии не обнаруживались, а затем популяция одной из них (Peptostreptococcus spp.) восстанавливалась, а другой (VeiUonella spp.) - нет. Содержание пептострептококков характеризовалось более выраженным увеличением на 14-е сутки $(5,0 \mathrm{lg}$ CFU), а количество Prevotella oralis во все сроки исследования мало отличалось от аналогичных значений у здоровых лиц (4,0-5,0 CFU).

Такое превышение выявлено во все сроки после имплантации для Actinomyces naeslundii, на 3-й сутки для Actinomyces israelii и на 7-е сутки для пародонтопатогенных бактероидов Prevotella melaninogenica и Porphyromonas gingivalis. Только на 14-е сутки после протезирования наблюдали снижение количества этих видов бактерий до $10^{4} \mathrm{CFU}$. Более чувствительными к комплексному лечению (гигиенические и антибактериальные мероприятия в послеоперационном периоде) оказались Actinomyces israelii и Fusobacterium -эти бактерии с 7-го дня после имплантации не определялись. Это, по-видимому, свидетельствует о благоприятных результатах данного этапа лечения.

Таким образом, у пациентов 1-й группы наблюдали изменение как качественного состава флоры (частота выделения отдельных видов), так и количества выделяемых микробов, которое, кроме того, подвергалось определённой динамике на 7-е и 14-е сутки наблюдения. На хирургическом этапе лечения, происходили весьма значительные изменения качественного (видового) и количественного состава микрофлоры по сравнению с исследованиями до операции. На 7-е и далее, на 14-е сутки исследования, наблюдали постепенное уменьшение доли облигатно-анаэробных и, прежде всего, вирулентных пародонтопатогенных видов (хотя полного их исчезновения не происходило). Кроме того, восстанавливалось и приближалось к норме количество стабилизирующих видов микробов. В качестве положительного факта, 
свидетельствующего о благоприятных результатах хирургического этапа лечения, следует также отметить, что количество большинства патогенных видов снижалось к 14-у дню с момента операции до минимальных значений.

\section{ЛИТЕРАТУРА}

1. Р.В.Ушаков, К.М. Кочемасов. Алгоритм принятия решения о проведении дентальной имплантации у пациентов с полной адентиией нижней челюсти.- Стоматолог.-2006.-№1.-с.13-17.

2. Царев В.Н., Абакаров СИ., Умарова С.Э. Динамика колонизации микробной флорой полости рта различных материалов, используемых для зубного протезирования // Стоматология. - 2000. - т. 79. № 1. - С. $55-57$.

3. Misch C.E. Contemporary Implant Dentistry. $-2^{\text {nd }}$ ed. - Mosby, Inc., 2013. -684 p.

4. Moore W.E. The bacteria of periodontal diseases/W.E. Moore, L.V. Moore//Periodontology.-2014. Vol. 5. - P. 66-77.

5. Lilly D.M. Growth promoting factor produced by microorganisms / D.M. Lilly // Science.- 2005.- V. 147.P. 747-748. 